\title{
Optimal Placement of Distributed Generation Units in Radial Distribution System using Hybrid Techniques
}

\author{
Banka Jyothsna Rani, Ankireddipalli Srinivasula Reddy
}

\begin{abstract}
Reconfiguration is a process that supports to eliminate the power loss from a distribution network and this process have the capability to reduce the losses up to a specific point. Additionally, loss minimization may be calculated through the presentation of Distributed Generation (DG) units. Conversely, the incorporation of DG into the distribution network at an improper position may cause higher in losses and fluctuations in voltage. In the meantime, the uncertainty in voltage may produce partial power failure in the system. For that reason, it is essential to deliberate the stability boundaries in DGs position and sizing in the Radial Distribution System (RDS). In this research paper, hybrid Binary Particle Swarm Optimization (BPSO) with Flower Pollination Algorithm (FPA) is proposed for the ideal reconfiguration process and placing the $D G$ in the 69-bus RDS. BPSO is applied to identify the best DG reconfiguration and FPA is proposed to determine the optimal DG size. This technique narrowly changes the DG location in every load bus of the network that delivers the minimum value of the objective function, which is considered as the finest candidate for DG connection. The simulation outcomes indicate the proposed method is more effective in reducing the power loss from 224.9804 to $27.2183 \mathrm{KW}$ with the reduction of $88.8972 \%$ when compared to existing algorithm.
\end{abstract}

Index Terms: Binary Particle Swarm Optimization (BPSO), Distributed Generation (DG), Flower Pollination Algorithm (FPA), Radial Distribution System (RDS), Reconfiguration.

\section{INTRODUCTION}

Reconfiguration is one of the best methods for loss minimization in a distribution network [1] and it can be frequently interconnected with other system. [2]. Thus, switching processes are mutual in a distribution system to pass on load from one line to another line even though maintain functioning arrangement as radial [3]. This kind of processes are referred as reconfiguration process that can be accomplished by sectionalizing the tie line switches. Meanwhile considering the loss minimization, reconfiguration process enhances additional functioning constraints for instance voltage stability and load assessment

Revised Manuscript Received on December 30, 2019.

* Correspondence Author

Banka Jyothsna Rani*, Department of Technical Education, Government Model Residential Polytechnic, Madanapalle (Andhra Pradesh) India. E-mail: jyothsna.jyothsna3@gmail.com

Dr. Ankireddipalli Srinivasula Reddy, CMR Engineering College, Hyderabad (Telangana) India. E-mail: svas_a@yahoo.com

(C) The Authors. Published by Blue Eyes Intelligence Engineering and Sciences Publication (BEIESP). This is an open access article under the CC BY-NC-ND license (http://creativecommons.org/licenses/by-nc-nd/4.0/) among the system tools [4], [5]. DG, a word generally applied for small-scale industries, also provide an advanced resolution for several experiments. The presence of DG is a significant part in reconfiguration process which leads to save more power loss, decrease the drained current from central substations, provide stable feeder loads and enhancement in the voltage magnitude [6]. Power losses surely have an important effect on the revenues of electric power companies, greenhouse gases emission, and the cost of the energy supplied [7].

Installing DG units in distribution systems have been proposed as an effective measure to minimize losses [8] Even though reconfiguration of systems is an operational process which can be exploited in scheduling researches along with various explanation [9]. This process indicates clearly that the outcomes of ideal DG placement completely depends upon the reconfiguration of a network. Furthermore, the existence of DG sometimes disturbs the reconfiguration outcomes that have declared previously. For that reason, the optimal results are accomplished by placing the DG at optimal position, while it deliberates the position of sectionalizing switches too, which is already present in the scheduling point [10], [11]. As a result, a method for the assortment of ideal allocation and sizing of the DG desires to be established and confirm the optimal configuration at same time [12]. When the DG is integrated with the system, the distribution system changed in the form of passive network to an active network. When the DG is fixed in a random or unfair position that provides more power loss and reduce the voltage stability [13]. The size, position, and configuration of the hardware components of the DG is decided based on the cost of the power and power distribution loss [14]. The growth of machineries and variants in the load demand plays an important role in the development of power generation and management [15]. First, candidate buses are checked with reconfiguration process (BPSO), then the proposed FPA is applied to assume the sizing from the selected buses.

The major contribution of this research comprises:

1. DG placement along with reconfiguration process is taken out in a cooperative scheme to examine system proficiency in power loss reduction and voltage stability improvement.

2. The hybrid BPSO-FPA clarifies the nonlinear optimization problem.

3. This method id is fast and accurate in the determination of DG optimal locations and size.

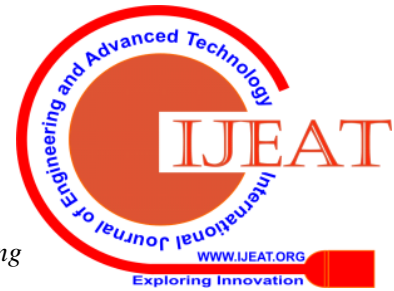




\section{Optimal Placement of Distributed Generation Units in Radial Distribution System using Hybrid Techniques}

\section{LITERATURE WORKS}

Researchers have suggested several methods or algorithms on DG allocation. This segment provides a descriptive evaluation of some important research contributions of DG allocation in the system.

Singh et al. [16] presented an impact assessment of DG in distributed systems from the reduction of power loss perspective by optimal power flow algorithms. DG units can be positioned at optimal sites where they deliver the finest decrease in feeder losses. The cost for real power and reactive power reduces with an increase in the size of DG and power factor from 0.80-to- 0.99.

Quadri, I.A., Bhowmick, S. and Joshi, D. [17] proposed a Hybrid Teaching Learning Based Optimization (HTLBO) method for the ideal allocation of DGs. HTLBO method is able to control both discrete and continuous variables. Teaching phase of TLBO and local pitch modification of the harmony search method completely based on the Auto Selection Rate (ASR). Also it has the capability to run away from effective local minima and maxima trappings. But ASR is not static in nature; so it altered in each and every iteration.

K. Muthukumar, S. Jayalalitha, [18] demonstrated the Harmonic Search Algorithm (HAS) which are perceptively enhanced through Particle Artificial Bee colony (PABC) method to attain the best solution within the search space and reduce the power loss. The allocation of devices has advancements in new transmission \& distribution network construction and improves the reliability of the system. The main drawback of this method is that the number of iterations increases to find an optimal solution.

Ghatak et al. [19] presented PSO algorithm with standard inertia weight to detect the optimal placement of the DG and distribution static compensator (DSTATCOM). This system has many advantages such as small size, no noise, and a low harmonic content when related to conventional reactive power compensating devices. But this method was not suitable for a large distribution system because it having several tie-switches and needs a lot of effort to create loops and also random opening of tie switches operation results in a slow convergence.

T.T. Nguyen et al. [20] proposed Meta heuristic adaptive Cuckoo Search method for recognizing the optimal position and sizing of DG. The exploration space of every tie-line influenced by graph model. This method improving the solution accuracy and convergence speed of the system. A large quantity of improbable individuals which disturbs the radial limit. Also, the reconfiguration process of the RDS is not discussed in this method.

\section{PROPOSED METHODOLOGY}

This research explores feeder reconfiguration in RDS and provides an efficient hybrid BPSO-FPA method to optimize systems with the help of reconfiguration and allocation of DG. Incorporating DG significantly minimize the power loss and maximizes the stability of the voltage profile. To acquire determined compensation from DG resources, it should to be synchronized with best location and size. It is necessary to allocate DG units at the optimal location with a suitable size to maximize techno-economic benefits. It results in benefits like minimization of overall system power loss, operation and maintenance cost, and enhancement in voltage profile, power quality, system stability, and reliability [21]. The block diagram for the proposed technique with DG placement is illustrated in the following Fig.1. The output value of DG must be in the range of minimum and maximum of active power and reactive power which is given in Eq. (1) and (2).

$P_{D, G_{i}}^{\min } \leq P_{D g, i} \leq P_{D G, \mathrm{i}}^{\max }$

$Q_{G, \text { min }} \leq Q_{G} \leq Q_{G, \max }$

(2)

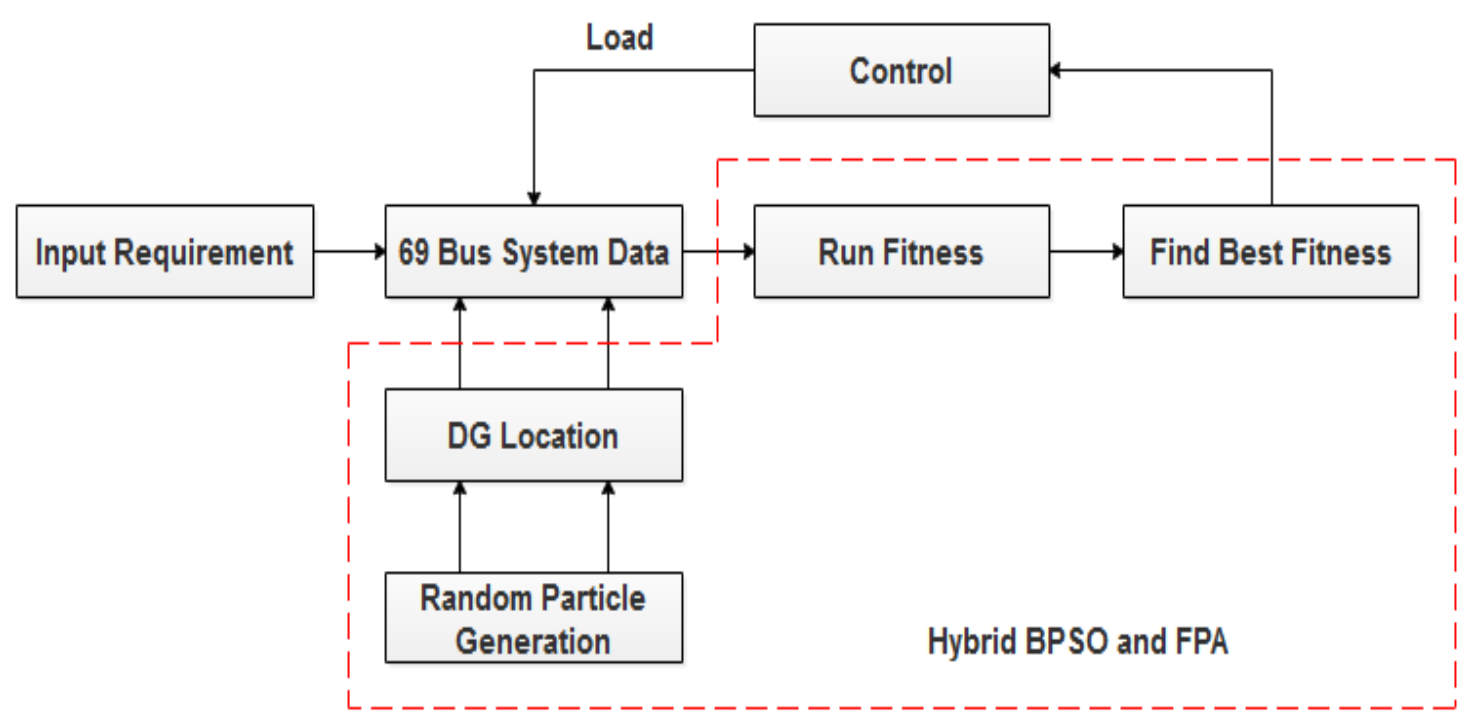

Fig.1. Block diagram of the proposed technique 
Step 1: Initialize the process with common control parameters that are present inside the algorithm.

Step 2: Read the line data and bus data for IEEE-69 bus radial distribution system.

Step 3: In the above-mentioned data, first random particle generation process will occur. And, load flow analysis will be checked.

Step 4: And then, run the fitness function of this research algorithm.

Step 5: From the data, find the best fitness values that will be given to system data, which will be processed again for the next iteration.

Step 6: While considering the BPSO-FPA, load flow analysis will be tested with a proposed technique to identify the optimal fitness values.

Step 7: Initially, random location will be given to find the optimal fitness values for optimal DG placement. In order to control the real/reactive power values, the best location of DG can be calculated.

Step 8: From the best values, DG will be optimally located by means of the proposed method, and multi-objectives will be evaluated with proper placement of DG.

\section{A. Optimal DG placement using hybrid BPSO-FPA}

In order to discover the appropriate position of DG, numerous researches have been done based on the optimization issues, which are discrete in nature and categorized as combinational optimization difficulties. The general PSO methodology is not suitable for finding the appropriate placement of DG in power production systems because of continuous property of PSO. In this research, the Binary form of the PSO algorithm is utilized and considered as an alternative solution for the different kinds of optimization issues. BPSO is utilized in this paper for discovering the variables from the appropriate space which makes the power system become convenient. The typical IEEE 69-bus RDS is used to verify the results of the proposed BPSO-FPA methodology.

The BPSO creates the set of initial particles, bit strings, constrains and velocity value in the interval of [0 1]. Hence, in this research, BPSO algorithm is utilized to improve the steadiness of the distribution system by minimizing the power losses.

In PSO, the position and the velocity of each particle at the iteration $k$ in the search space are described by $X_{k}^{i}$ and $V_{k}^{i}$. The velocity of the particle $I$ in the iteration $k+1 P_{l b e s t}^{i}$ is obtained from the following Eq. (3).

$$
\begin{aligned}
& V_{k+1}^{i}=\omega \cdot V_{k}^{i}+C 1 . R 1\left(P_{l b s e t}^{i}-X_{k}^{i}\right)+ \\
& C 2 . R 2\left(P_{\text {global }}^{i}-X_{k}^{i}\right)
\end{aligned}
$$

(3)

Where $R 1$ and $R 2$ are the random functions and $C 1, C 2$ are the training coefficients. $\omega$ is the inertia weight factor and it can be attained from the following Eq. (4).

$\omega=\omega_{\max }-\left\{\left(\omega_{\max }-\omega_{\min }\right)-k_{\max }\right\} \times k$

(4)

Where $k_{\max }$ is the number of the maximum iteration. At the termination of each and every iteration, a new position for each particle is obtained by summing of old position and new velocity which is expressed in Eq. (5).

$X_{k+1}^{i}=X_{k}^{i}+V_{k+1}^{i}$

(5)

The swarm formulation remains unchanged. A logistic transformation $S\left(V_{k}^{i}\right)$ is exploited to accomplish this modification that is written in Eq. (6) and (7).

$S\left(V_{k+1}^{i}\right)=\operatorname{sig} \bmod e\left(V_{k+1}^{i}\right)=\frac{1}{1+\exp \left(V_{k+1}^{i}\right)}$

(6)

If rand $\alpha S\left(V_{k+1}^{i}\right)$ then $: \mathrm{X}_{k+1}^{i}=1$; then:

(7)

Else: $X_{k+1}^{i}=0$;

The function $S\left(V_{k}^{i}\right)$ is a sigmoid restrictive transformation and rand is a quasi-random number designated from a constant distribution in [0,1]. Eq. (8), (9) and (10) describe the limits of the particle's dimension.

$1 \alpha B_{i} \alpha B_{\max }$

$0 \alpha P_{i} \alpha P_{\max }$

(9)

$T_{i}=\left\{1,2, \ldots T_{f}\right\}$

In this research, novel optimization method depends on FPA which has been applied for optimum sizing of DGs. The main intention of FPA is the optimal replica of plants in terms of quantities as well as magnitudes. It is absolutely novel optimization depends on characteristics of flower pollination. The primary rule plus flower dependability can be characterized statistically as Eq. (11).

$X_{i}^{t+1}=X_{i}^{t}+L\left(X_{i}^{t}-g_{*}\right)$

Where $X_{i}^{t}$ is the pollen i or solution vector $X_{i}$ at iteration count $\mathrm{t}$, and $g_{*}$ is the present optimal result establish between every results at the existing iteration count. The constraint $\mathrm{L}$ is the strong point of the pollination that fundamentally called step size. Since bugs might change over a lengthy space with several distance stages which is written as Eq. (12).

$L \approx \frac{\lambda \Gamma(\lambda) \sin (\pi \lambda / 2)}{\pi} \frac{1}{S^{1+\lambda}}$

That is for $L>0$ from a Levy distribution where $\Gamma(\lambda)$ the regular gamma function, and its distribution is effective for huge steps $\mathrm{s}>0$. Here $\lambda=1.5$ is used. The local pollination is written as Eq. (13).

$X_{i}^{t+1}=X_{i}^{t}+\in\left(X_{j}^{t}-X_{k}^{t}\right)$ 


\section{Optimal Placement of Distributed Generation Units in Radial Distribution System using Hybrid Techniques}

Where $X_{j}^{t}$ and $X_{k}^{t}$ are pollen from various flowers of the similar plant. This might be fundamentally copycats the flower dependability in an inadequate community. This becomes consistently a local indiscriminate walk if we appeal $\in$ from a constant distribution [0,1]. The flowchart for hybrid algorithm is illustrated in below figure 2 .

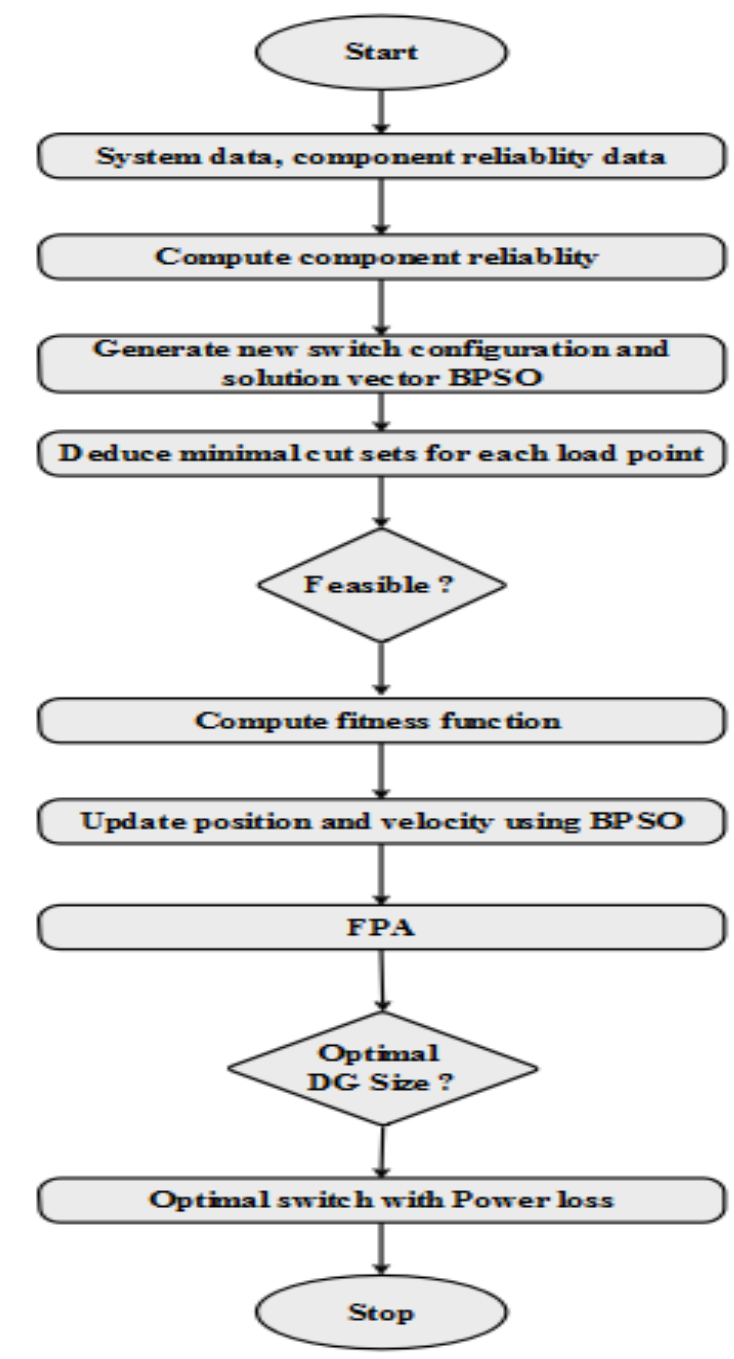

Fig.2. The steps of optimal DG placement using hybrid BPSO-FPA is given as follows:

Step 1: There are various inputs given in the BPSO initialization. Those are line data, bus data, generator data and load data. During the initialization progress, the size of the population of the particles and iterations are set, the position and velocity of the particles are randomly generated. Initially, there is a need to allocate number of iteration count $k=0$ and then start the process.

Step 2: The computation of the objective function is approved by "Newton-Raphson Load flow analysis"

Step 3: The objective value of each particle is compared with its individual best. This individual best is taken as current pbest when the objective value is smaller than the pbest as well as the corresponding position is recorded.

Step 4: The candidate particle that has the lowest own best is pbest, and allocate the value of this pbest as the current best value (gbest) .

Step 5: The position and the velocity of every particle are simplified by means of aforementioned equation.

Step 6: when the count of iteration reaches the threshold value, go to Step 8. Otherwise, set iteration index $k=k+1$, and go back to Step 2 .

Step 7: The optimal values from the BPSO such as DG location and size are given as the input to FPA for identifying the best position and size. FPA received the DG location and size from the BPSO to identify the excellence of the solution. Step 8: A candidate particle is elected from $n$ (number of solution particle) randomly, when the excellence of updated particle solution in the elected particle is better than the existing solution, then the existing solution is replaced by the updated particle solution.

Step 9: The inferior solution is rejected based on the probability and new solutions are generated using Eq. (13).

Step 10: In this research, the stopping criterion is set as a maximum generation of 100 iterations. The iteration stopped, when reaching the stopping criterion, and the result of FPA is obtained.

\section{RESULT AND DISCUSSION}

The simulation outcomes of BPSO-FPA technique for the RDS with the inclusion of DGs helps to decrease the losses and also increases the voltage profile of the system. BPSO-FPA is more appropriate to examine for the finest switch arrangement of RDS with DG. The efficiency of BPSO-FPA technique is examined in 69-bus RDS. In the meantime, DGs are generally connected at limited number of positions and its analytical results are attained from every candidate. Conversely, certain analytical results may disturb the parameter limits and turn out to be complex. So these above mentioned problems are modified by BPSO-FPA technique. BPSO exploration process has been employed in examining inside the assembly to increase search effectiveness and eliminate early maturing. In BPSO-FPA technique, BPSO identifies the test system through load flow for reconfiguring the system with optimal DG placement and then FPA is used for identifying the DG rating. The simulation outcomes indicate that BPSO-FPA for RDS with DG, which decrease the losses and produce support to the stability. BPSO-FPA is appropriate to discover for the best switch combination of 69-bus RDS with optimal DG size. The comprehensive arrangement of the work to resolve the best DG position and sizing of the 69 test systems are done by means of BPSO-FPA. Initially the total loss is deliberated from load flow analysis. Afterwards, the DG and its size varied by using the FPA procedure. For various DG sizes, power losses are calculated.

This arrangement works with the subsequent structure, which has 8 feeder lines, 68 sectionalizing switches and 5 tie-lines. The execution of the BPSO-FPA method comprises four different scenarios that are deliberated to analyze the advantage of the suggested method.

Scenario I: 69 RDS with reconfiguration;

Scenario II: 69 RDS with DG Units alone reconfiguration and installation of single DG unit;

Scenario III: Reconfiguration with single DG units;

Scenario

Reconfiguration with multi DG units; 
For deliberating scenario 1, the considered RDS has include the process of reconfiguration alone without the inclusion of DG units. The resulting voltage profile of the 1st scenario is illustrated in following Fig. 3 and the equivalent standards are obtained in table 1 .

From the table 1, it clearly shows the power loss reduction of $62.3642 \%$ after changing the switch reconfiguration which is much better than before the reconfigured process.

Table I. Comparison table for first scenario

\begin{tabular}{|c|c|c|}
\hline Scenario 1 & $\begin{array}{c}\text { BEFORE } \\
\text { Reconfiguration }\end{array}$ & $\begin{array}{c}\text { AFTER } \\
\text { Reconfiguration }\end{array}$ \\
\hline Tie switches & 6970717273 & 49111923 \\
\hline Power loss & $224.9804 \mathrm{~kW}$ & $84.6731 \mathrm{KW}$ \\
\hline Power loss reduction & ----------- & $62.3642 \%$ \\
\hline Minimum voltage: & $0.90919 \mathrm{pu}$ & 0.94722 \\
\hline
\end{tabular}

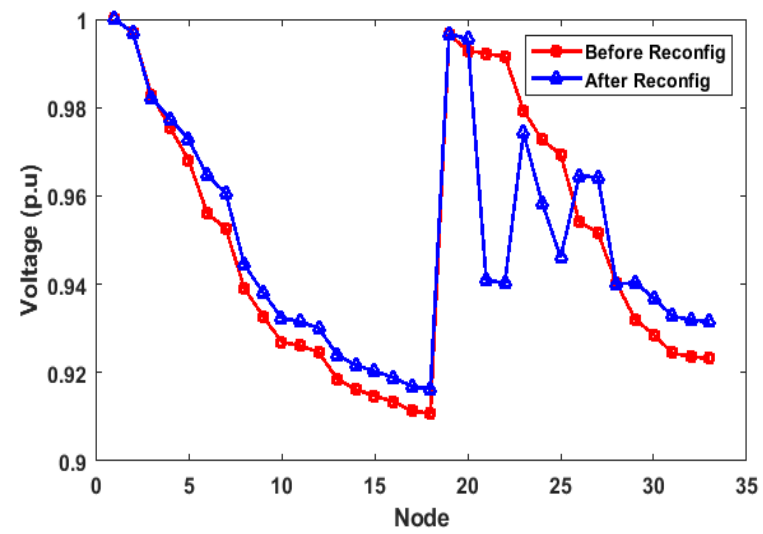

Fig.3. The resultant data for the first scenario

In scenario 2, the deliberated test system (69 bus) has computed with only DG. In this process, DGs are placed in a random position for enhancing the voltage profile and decreasing the power loss. The comparative analysis of the $2^{\text {nd }}$ scenario is existed in the following table 2 and the voltage profile diagram for this scenario is illustrated in following Fig. 4. From the table 2, it shows the power loss reduction of $66.1507 \%$ which is much better than before placing the DGs.

Table II. Results for second scenario

\begin{tabular}{|c|c|c|}
\hline Scenario 2 & BEFORE DG & AFTER DG \\
\hline Tie switches & 6970717272 & 6970717273 \\
\hline Power loss & $224.9804 \mathrm{~kW}$ & $76.1249 \mathrm{~kW}$ \\
\hline Power loss reduction & ---------- & $66.1507 \%$ \\
\hline Size of DG & $0.1018 \mathrm{MW}$ & $0.4 \mathrm{MW}[25]$ \\
\hline Minimum voltage: & 0.9677 & 0.9542 \\
\hline
\end{tabular}

For Scenario 3, the benchmark system is taken into account with the process of reconfiguration and presence of a single DG. The resulting voltage stability of 3rd scenario is illustrated in the Fig. 5 and the equivalent statistical outcomes are offered in the table 3 which signifies the best DG sizing with the reconfiguration process. From this table, it clearly determined that single DG placement with reconfiguration at a size of $0.4 \mathrm{MW}$ decrease the losses from $224.9804 \mathrm{~kW}$ to $36.6369 \mathrm{~kW}$ which shows $83.7083 \%$ of overall reduction. The proportion of developments in power losses indicates better results when compared to above mentioned scenario. It

can be determined that bus 36 is the optimal bus for suitable DG allocation through a size of 0.4 MW.

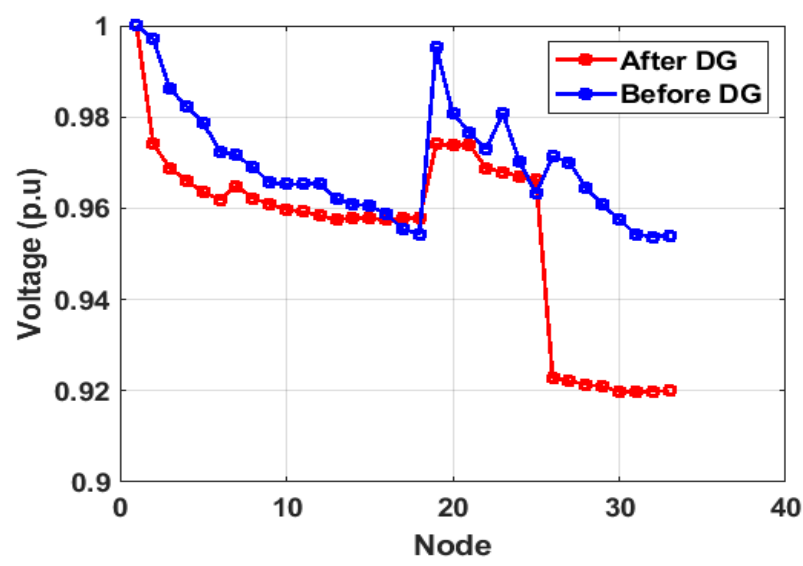

Fig.4. The resultant data for the second scenario

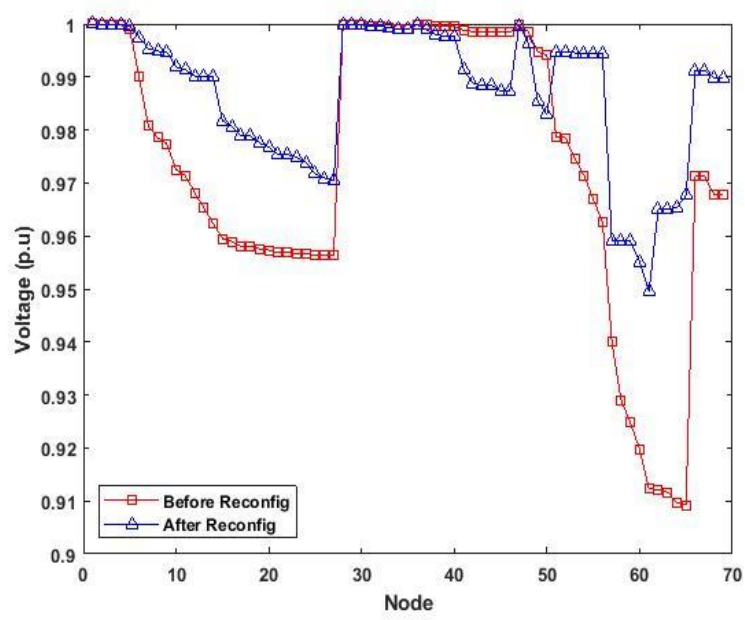

Fig.5. The result for the third scenario

Table III. Comparison for third scenario

\begin{tabular}{|c|c|c|}
\hline Scenario 3 & $\begin{array}{c}\text { BEFORE } \\
\text { Reconfiguration } \\
\text { with DG }\end{array}$ & $\begin{array}{c}\text { AFTER } \\
\text { Reconfiguration } \\
\text { with DG }\end{array}$ \\
\hline Tie switches & 6970717273 & 574386522 \\
\hline Power loss & $224.9804 \mathrm{~kW}$ & $36.6369 \mathrm{~kW}$ \\
\hline Power loss reduction & ---------- & $83.7083 \%$ \\
\hline Minimum voltage: & $0.90919 \mathrm{pu}$ & 0.94947 \\
\hline Size (location of DG) & $0.4 \mathrm{KW}$ & $0.4 \mathrm{MW}(36)$ \\
\hline
\end{tabular}

Table IV. Comparison for fourth scenario

\begin{tabular}{|c|c|c|}
\hline Scenario 4 & $\begin{array}{c}\text { BEFORE } \\
\text { Reconfiguration } \\
\text { with DGs }\end{array}$ & $\begin{array}{c}\text { AFTER } \\
\text { Reconfiguration } \\
\text { with DGs }\end{array}$ \\
\hline Tie switches & 6970717273 & 530422128 \\
\hline Power loss & $224.9804 \mathrm{~kW}$ & $27.2183 \mathrm{~kW}$ \\
\hline Power loss reduction & ---------- & $88.8972 \%$ \\
\hline Minimum voltage: & $0.90919 \mathrm{pu}$ & $0.95962 \mathrm{pu}$ \\
\hline Size (location of DG) & $0.4 \mathrm{MW}$ & $0.4 \mathrm{MW}(844 \mathrm{31})$ \\
\hline
\end{tabular}

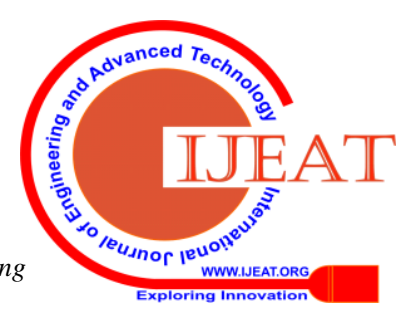




\section{Optimal Placement of Distributed Generation Units in Radial Distribution System using Hybrid Techniques}

The radial test bus arrangement contains reconfiguration process with the integration of multiple DGs which are deliberated as scenario 4 . The statistical analysis of the resulting voltage is represented in the table 4.

From this table 4, it determined that BPSO-FPA procedure decreases the value of the total loss from $224.9804 \mathrm{~kW}$ to $27.2183 \mathrm{~kW}$ which indicates $88.8972 \%$ of overall loss decrease.

The voltage stability for fourth scenario is shown in figure 6 . The aggregate improvement in total losses from the overall scenarios produces the better results which are depicted in the table 5 . The enhancement in voltage parameter and reduction in losses can be attained with the help of optimal placement.
Furthermore, the proposed technique is quick and simple in resolving RDS problems. Additionally, one more advantage of this system is that it informs the multipliers strongly and its subsequent effects are further fast and precise. Table 5 demonstrates the comparative analysis for all scenarios along with existing methods. The efficiency and performance of RDS reconfiguration are broadly explained by the efficient searching method. BPSO-FPA is a type of swarm intelligence optimization procedure, a modest, simple and easy way to attain the optimal result. The proposed BPSO-FPA not only decreases the power loss but also supports the stability of voltage.

Table V. Comparison table for all scenarios

\begin{tabular}{|c|c|c|c|c|}
\hline Scenarios & $\begin{array}{l}\text { Stud Krill Herd Algorithm } \\
\text { (SKHA) [22] }\end{array}$ & BPSO Algorithm [23] & $\begin{array}{c}\text { Hybrid BPSO-KGMO } \\
{[24]}\end{array}$ & Proposed BPSO-FPA \\
\hline Scenario 1 & $\begin{array}{c}\text { Tie switch = } 6918135661 \\
\text { Power loss = 99.35 } \\
\text { Power loss reduction = 55.85 } \\
\% \\
\text { Min voltage = } 0.9428 \\
\end{array}$ & $\begin{array}{c}\text { Tie switch = } 1456616970 \\
\text { Power loss }=98.5952 \\
\text { Power loss reduction }= \\
56.1761 \% \\
\text { Min voltage }=0.94947 \\
\end{array}$ & $\begin{array}{c}\text { Tie switch }=34141923 \\
\text { Power loss }=90.0212 \mathrm{~kW} \\
\text { Power loss reduction } \\
=60.587 \% \\
\text { Min voltage }=0.94947 \mathrm{pu}\end{array}$ & $\begin{array}{c}\text { Tie switch =4 } 9111923 \\
\text { Power loss }=84.6731 \mathrm{~kW} \\
\text { Power loss reduction } \\
=62.3642 \% \\
\text { Min voltage }=0.94722 \mathrm{pu}\end{array}$ \\
\hline Scenario 2 & $\begin{array}{c}\text { Tie switch = } 6970717272 \\
\text { Power loss = 86.77 } \\
\text { Power loss reduction = } 61.43 \\
\% \\
\text { Min voltage }=0.9697\end{array}$ & $\begin{array}{c}\text { Tie switch = } 6970717273 \\
\text { Power loss = 82.1119 } \\
\text { Power loss reduction = } 63.488 \\
\quad \% \\
\text { Min voltage }=0.9494\end{array}$ & $\begin{array}{c}\text { Tie switch = } 69707172 \\
73 \\
\text { Power loss }=80.9479 \\
\text { Power loss reduction }= \\
64.0062 \% \\
\text { Min voltage }=0.94693\end{array}$ & $\begin{array}{c}\text { Tie switch = } 6970717273 \\
\text { Power loss = } 76.1249 \\
\text { Power loss reduction }= \\
66.1509 \% \\
\text { Min voltage }=0.9542\end{array}$ \\
\hline Scenario 3 & $\begin{array}{c}\text { Tie switch }=6918135661 \\
\text { Power loss }=51.30 \\
\text { Power loss reduction }=77.2 \% \\
\text { Min voltage }=0.9619\end{array}$ & $\begin{array}{c}\text { Tie switch }=40605306 \\
\text { Power loss }=46.9193 \mathrm{~kW} \\
\text { Power loss reduction }=79.137 \\
\% \\
\text { Min voltage }=0.94693\end{array}$ & $\begin{array}{c}\text { Tie switch }=62665455 \\
23 \\
\text { Power loss }=38.9642 \mathrm{~kW} \\
\text { Power loss reduction }= \\
82.6744 \% \\
\text { Min voltage }=0.94947\end{array}$ & $\begin{array}{c}\text { Tie switch }=574386522 \\
\text { Power loss = } 36.6369 \mathrm{~kW} \\
\text { Power loss reduction }= \\
83.7083 \% \\
\text { Min voltage }=0.94947\end{array}$ \\
\hline Scenario 4 & $\begin{array}{c}\text { Tie switch = } 6917135861 \\
\text { Power loss }=40.30 \\
\text { Power loss reduction }=82.08 \\
\% \\
\text { Min voltage }=0.9736 \\
\text { DG size (location) }= \\
1.0666(61), 0.3525(60) \\
0.4527(62)\end{array}$ & $\begin{array}{c}\text { Tie switch = } 1714481336 \\
\text { Power loss = } 35.9239 \mathrm{~kW} \\
\text { Power loss reduction }=84.026 \\
\% \\
\text { Min voltage }=0.95907 \\
\text { DG size (location) }=0.4(21) \\
0.4(32), 0.4(63)\end{array}$ & $\begin{array}{c}\text { Tie switch = } 56112234 \\
48 \\
\text { Power loss = 28.5472 kW } \\
\text { Power loss reduction = } \\
87.3064 \% \\
\text { Min voltage }=0.94693 \mathrm{pu} \\
4 \mathrm{KW}(41467)\end{array}$ & $\begin{array}{c}\text { Tie switch = } 530422128 \\
\text { Power loss = } 27.2183 \mathrm{~kW} \\
\text { Power loss reduction = } \\
88.8972 \% \\
\text { Min voltage = } 0.95962 \mathrm{pu} \\
0.4 \mathrm{MW}\left(\begin{array}{lll}8 & 44\end{array}\right)\end{array}$ \\
\hline
\end{tabular}

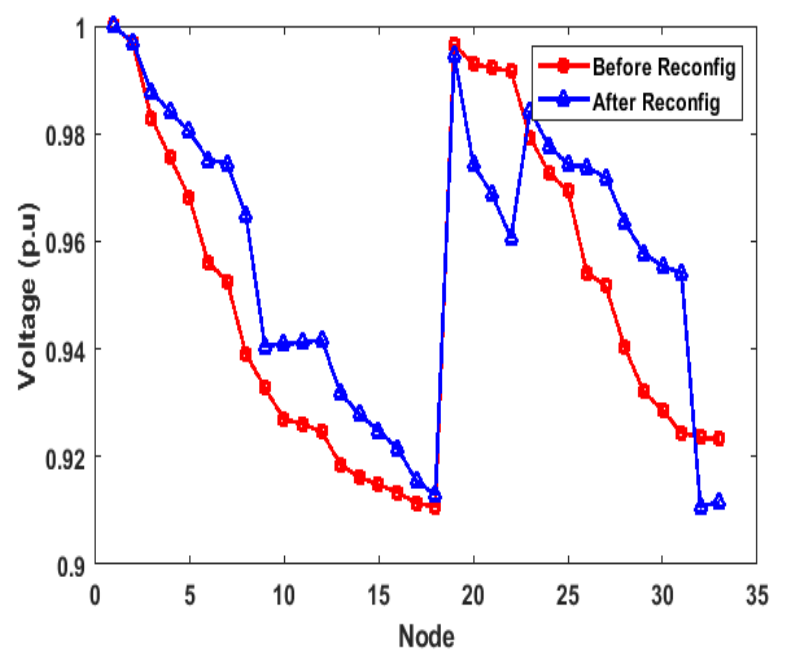

Simulation results of proposed method is compared with existing techniques name called SKHA [22], BPSO [23] and BPSO-KGMO [24] which is tabulated in table 5. From the comparison, it clearly shows proposed BPSO-FPA is much superior to all the above mentioned methods in all the scenarios. A simple load flow analysis is used and its multi-objective function is conveyed to resolve the problematic which includes power loss and voltage profile. The main objective of this research is to discover ideal sizing and assignment of DGs for upgrading the voltage stability in terms of power loss reduction. 
BPSO-FPA technique is verified on a typical IEEE-69 bus RDS which shows that results are improved in a very significant manner. Especially in scenario 4,

proposed BPSO-FPA shows the power loss reduction of 88.8972\% by placing multiple DGs in particular places (8 44 31 ) to reduce the power loss which is much better when associated with existing techniques.

\section{CONCLUSION} improve the efficiency of the network amongst DG placement and reconfiguration of a network. Researchers and operators keep focus on advancing their determinations to resolve the distribution system issues interrelated to voltage profile and power loss which is completely based on an optimal position of DG resources. In this research, a controlling algorithm named as BPSO-FPA is proposed for ideal allocations and sizing of DG in radial distribution systems. Furthermore, the results are presented to validate the efficiency of the proposed method to decrease the losses and enhance the voltage profile. The simulation outcomes specified that the complete influence of the DG on voltage stability is progressive and a comparable decrease in power losses of $88.8972 \%$ is accomplished. But, it can be restricted that optimal results can be attained with various types of DGs. In future, the proposed technique will be suggested for unbalanced RDS and also for large scale systems with different DG units.

\section{REFERENCES}

1. L. W. de Oliveira, F. S. Seta, and E. J. de Oliveira. (2016). Optimal reconfiguration of distribution systems with representation of Electrical Power \& Energy Systems 83. pp. 382-391.

2. R. S. Rao, K. Ravindra, K. Satish, and S. V. L. Narasimham. (2012). Power loss minimization in distribution system using network reconfiguration in the presence of distributed generation. IEEE

3. I. B. Hamida, S. B. Salah, F. Msahli, and M. F. Mimouni. Optimal network reconfiguration and renewable DG integration considering time

4. J. C. López, M. Lavorato, and M. J. Rider. (2016) Optimal indices improvement. International Journal of Electrical Power \& Energy Systems. 78. pp. 837-845.

5. K. Liu, W. Sheng, Y. Liu, X. Meng, and Y. Liu. (2015). Optimal sitting and sizing of DGs in distribution system considering time sequence characteristics of loads and DGs. International Journal of Electrical Power \& Energy Systems. 69. pp. 430-440.

6. S. Das, D. Das, and A. Patra. (2017). Reconfiguration of distribution networks with optimal placement of distributed generations in the presence of remote voltage controlled bus. Renewable and Sustainable Energy Reviews. 73. pp. 772-781.

7. S. Sannigrahi, and P. Acharjee. (2018). Maximization of System Benefits with the Optimal Placement of DG and DSTATCOM Considering Load Variations. Procedia computer science.143. pp. 694-701.

8. A. M. Imran, M. Kowsalya, and D. P. Kothari. (2014). A novel integration technique for optimal network reconfiguration and distributed generation placement in power distribution networks. International Journal of Electrical Power \& Energy Systems, 63. pp.461-472.

9. M. R. Kaveh, H. Rahmat-Allah, and S. M. Madani. (2018) Simultaneous optimization of re-phasing, reconfiguration and DG placement in distribution networks using BF-SD algorithm. Applied Soft Computing. 62. pp. 1044-1055.

10. P. C. Ramaswamy, J. Tant, J. Radhakrishna Pillai, and G. Deconinck. (2015). Novel methodology for optimal reconfiguration of distribution networks with distributed energy resources. Electric Power Systems Research. 127. pp. 165-176.
An ideal placement of DG is one of the finest methods to uncertainties through interval analysis. International Journal of transactions on power systems. 28(1). pp. 317-325. sequence variation in load and DGs. Renewable energy. 121. pp. 66-80. reconfiguration of electrical distribution systems considering reliability

11. S. Nikkhah, and A. Rabiee. (2019). Multi-objective stochastic model for joint optimal allocation of DG units and network reconfiguration from DG owner's and DisCo's perspectives. Renewable energy. 132. pp. 471-485.

12. R. Usharani, and S. Mishra. (2019). An improved Elitist-Jaya algorithm for simultaneous network reconfiguration and DG allocation in power distribution systems. Renewable Energy Focus. 30. pp. 92-106.

13. M. M. Aman, G. B. Jasmon, H. Mokhlis, and A. H. A. Bakar. (2012). Optimal placement and sizing of a DG based on a new power stability index and line losses. International Journal of Electrical Power \& Energy Systems. 43(1). pp. 1296-1304.

14. S. Kansal, V. Kumar, and B. Tyagi. (2013). Optimal placement of different type of DG sources in distribution networks. International Journal of Electrical Power \& Energy Systems. 53. pp. 752-760.

15. D. Q. Hung, and N. Mithulananthan. (2013). Multiple distributed generator placement in primary distribution networks for loss reduction. IEEE Transactions on industrial electronics. 60(4). pp. 1700-1708.

16. B. Singh, and B. J. Gyanish. (2018). Impact assessment of DG in distribution systems from minimization of total real power loss viewpoint by using optimal power flow algorithms. Energy Reports. 4. pp. 407-417.

17. I. A. Quadri, S. Bhowmick, and D. Joshi. (2018). A hybrid teaching-learning-based optimization technique for optimal DG sizing and placement in radial distribution systems. Soft Computing. pp.1-19.

18. K. Muthukumar, and S. Jayalalitha. Integrated approach of network reconfiguration with distributed generation and shunt capacitors placement for power loss minimization in radial distribution networks. Applied Soft Computing. 52. pp. 1262-1284.

19. S. R. Ghatak, S. Sannigrahi, and P. Acharjee. (2018). Comparative Performance Analysis of DG and DSTATCOM Using Improved PSO Based on Success Rate for Deregulated Environment. IEEE Systems Journal 12(3). pp. 2791-2802.

20. T. T. Nguyen, A. V. Truong, and T. A. Phung. (2016). A novel method based on adaptive cuckoo search for optimal network reconfiguration and distributed generation allocation in distribution network. International Journal of Electrical Power \& Energy Systems. 78. pp. 801-815.

21. S. S. KOLA. (2018). A review on optimal allocation and sizing techniques for DG in distribution systems. International Journal of Renewable Energy Research (IJRER). 8(3). pp. 1236-1256

22. S. A. ChithraDevi, L. Lakshminarasimman, and R. Balamurugan. (2017). Stud Krill herd Algorithm for multiple DG placement and sizing in a radial distribution system. Engineering Science and Technology, an International Journal. 20(2). pp. 748-759.

23. B. J. Rani, and A. S. Reddy. (2018). Optimal Allocation and Sizing of Multiple DG in Radial Distribution System Using Binary Particle Swarm Optimization. International journal of intelligent engineering and system. 12(1). pp. 290-299.

24. J. R. Banka, A. S. Reddy. (2019). Optimal Allocation of DG using Hybrid Optimization Technique for Minimizing the Power Loss. International Journal of Recent Technology and Engineering (IJRTE). $7(6)$.

\section{AUTHORS PROFILE}

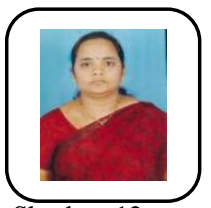

Mrs. B. Jyothsna Rani is presently pursuing her Ph.D from JNTU, Hyderabad, India. She has obtained her Master's degree in Power Systems from Nagarjuna University in the year 2010. She has obtained her Bachelor's degree in Electrical and Electronics Engineering from Andhra University in the year 2003. She has 12 years of experience in teaching. She is currently working as Lecturer in Electrical \& Electronics Engineering section in Department of Technical Education. She presented an international conference at Chennai in the year 2014. She has supervised 10 UG projects and 10 PG. Her areas of interest are optimal DG placement, power systems stability and FACTS devices

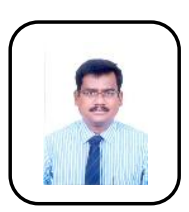

Dr. A. S. Reddy has been serving as the Principal of CMR Engineering College (CMREC) for the past 5 years. An ME and PhD (Electrical Engineering) holder with 20 years of experience, he has always played a pivotal role in the development of the CMREC. He own five National Awards. He has authored Two Textbooks and has published about 18 papers in International journals and presented about 15 papers in National and International Conferences. He is guiding 9 Ph.D scholars under JNTU. 